\title{
Survival and Complications in Pediatric Patients With Cancer and COVID-19: A Meta-Analysis
}

\author{
Elisa Dorantes-Acosta ${ }^{1 \dagger}$, Diana Ávila-Montiel ${ }^{2 \dagger}$, Miguel Klünder-Klünder $^{2}$, \\ Luis Juárez-Villegas ${ }^{3}$ and Horacio Márquez-González ${ }^{4,5 *}$ \\ ${ }^{1}$ Biobanco de Investigación en Células Leucémicas, Hospital Infantil de México Federico Gómez, México City, Mexico, \\ 2 Subdirección de Investigación, Hospital Infantil de México Federico Gómez, México City, Mexico, ${ }^{3}$ Departamento de Onco- \\ Hematología, Hospital Infantil de México Federico Gómez, México City, Mexico, ${ }^{4}$ Investigación Clínica, Hospital Infantil de México \\ Federico Gómez, México City, Mexico, ${ }^{5}$ Cardiopatías Congénitas. Hospital de Cardiología, Centro Médico Nacional Siglo XXI, \\ Instituto Mexicano del Seguro Social (IMSS), México City, Mexico
}

\section{OPEN ACCESS}

Edited by: Alan Wayne,

Children's Hospital of Los Angeles, United States

Reviewed by: Andrea Di Cataldo,

University of Catania, Italy

Sindhu Mohandas,

Children's Hospital of Los Angeles, United States

*Correspondence:

Horacio Márquez-González horaciohimfg@gmail.com

${ }^{\dagger}$ These authors have contributed equally to this work

Specialty section: This article was submitted to Pediatric Oncology, a section of the journal

Frontiers in Oncology

Received: 19 September 2020 Accepted: 02 December 2020 Published: 21 January 2021

Citation:

Dorantes-Acosta E, Ávila-Montiel D, Klünder-Klünder M, Juárez-Villegas L and Márquez-González H (2021)

Survival and Complications in Pediatric Patients With Cancer and COVID-19: A Meta-Analysis.

Front. Oncol. 10:608282. doi: 10.3389/fonc.2020.608282
Background: The pandemic caused by the novel severe acute respiratory syndrome coronavirus 2 (SARS-CoV-2) has affected all age groups, including the pediatric population, in 3-5\% of all cases. We performed a meta-analysis to understand the survival and associated complications in pediatric cancer patients as well as their hospitalization, intensive care, and ventilation care (supplemental oxygen/endotracheal intubation) needs.

Methods: A systematic search was performed using MEDLINE, TRIP Database, International Clinical Trials Registry Platform (WHO), The Cochrane Library, Wiley, LILACS, and Google Scholar. Additionally, a search using the snowball method was performed in Nature, New England Journal of Medicine, Science, JAMA, ELSEVIER editorial, Oxford University Press, The Lancet, and MedRxiv. Searches were conducted until July 18, 2020. A total of 191 cancer patients with coronavirus disease 2019 (COVID-19) were integrated from 15 eligible studies. In a sub-analysis, patients were stratified into two groups: hematological cancer and solid tumors. Outcome measures were overall survival, risk of hospitalized or needing intensive care, and need for ventilatory support in any modality. The random effects statistical analysis was performed with Cochran's chi square test. The odds ratio (OR) and heterogeneity were calculated using the $\mathrm{I}^{2}$ test.

Results: The overall survival was $99.4 \%$. There were no statistically significant differences in the risk of hospitalization between hematological malignancies and solid tumors (95\% confidence interval $[\mathrm{Cl}]$ 0.48-18.3; $\mathrm{OR}=2.94)$. The risk of being admitted to the intensive care unit was also not different between hematological malignancies and other tumors (95\% Cl 0.35-5.81; OR = 1.42). No differences were found for the need of ventilatory support (95\% Cl 0.14-3.35; OR = 0.68). Although all the studies were cross-sectional, the mortality of these patients was $0.6 \%$ at the time of analysis.

Conclusions: In the analyzed literature, survival in the studied group of patients with COVID-19 was very high. Suffering from hematological neoplasia or other solid tumors and COVID-19 was not a risk factor in children with cancer for the analyzed outcomes.

Keywords: severe acute respiratory syndrome coronavirus 2, coronavirus disease 2019, childhood cancer, meta-analysis, systematic review, mortality, ventilation, intensive care 


\section{INTRODUCTION}

Up to September 1, 2020, infection by the novel severe acute respiratory syndrome coronavirus 2 (SARS-CoV-2) causing coronavirus disease 2019 (COVID-19) that emerged in China, has caused 25,559,850 infections and 852,109 deaths. Although the exact number of infected children aged $<18$ years is imprecise, it is estimated to represent $1-5 \%$ of the total infections. Therefore, it is likely that $>1,000,000$ children are infected with this virus (1).

The severity and fatal outcomes of patients infected by SARS$\mathrm{CoV}-2$ are directly related to age, as demonstrated by Zhang et al., with a higher frequency of hospitalizations, mechanical ventilation requirement, and mortality in individuals aged $>60$ years (2). Simultaneously, pediatric patients have a limited capacity to follow basic measures to prevent contagion, thus creating a situation of public health risk (3).

The reported SARS-CoV-2 infection presents differences between adults and children, constituting a less severe and even asymptomatic condition in the latter (2). In China, Dong et al. published the first pediatric series in 2,143 children with a median age of 7 years and suspected SARS-CoV-2 infection, of which 728 (34.1\%) were confirmed using polymerase chain reaction (PCR) tests, and one adolescent male died (4). Similar outcomes were found in New York, which was one of the main epidemic centers. In this city, Richardson et al. described the characteristics of 5,700 infected patients, of which systemic arterial hypertension (SAH) represented $55.6 \%$ of the comorbidities; $34(6 \%)$ of patients were aged $<18$ years, and no deaths were reported (5).

For the infected pediatric population, Pathak et al. conducted a multicenter study in pediatric intensive care units that included 74 children and that was used as a base for a projection of 50,000 children with severe SARS-CoV-2 disease, of which 5,400 might need mechanical ventilation (6).

Considering that COVID-19 in adults has shown an association between the most prevalent comorbidities (obesity, $\mathrm{SAH}$, diabetes) and the development of severe respiratory complications, it is pertinent to perform the same analysis in the most frequent pediatric diseases, including cancer, one of the main causes of death in the world (7). In this regard, Chen et al. documented the first case in a child with acute lymphoblastic leukemia under treatment and infected with SARS-CoV-2 that simultaneously manifested with a neutropenic event and fever, for which the dynamic outcome was not clarified (8). A series of cases have been published from other pediatric cancer centers in countries that have been epicenters of the COVID-19 pandemic.

Because children with cancer require continuous chemotherapy, the dilemma arises whether to interrupt the therapy or to add up a risk condition that exposes them to the complications described so far caused by infection with SARS-CoV-2. The accelerated spread of the virus has led some international cooperative cancer centers to issue recommendations based on expert consensus $(3,9)$.

Based on the scientific evidence published to date, it is necessary to assess whether COVID-19 increases the risk of severe outcomes in patients with pediatric cancer.

\section{Objectives}

- To determine the difference in mortality in pediatric patients with cancer and COVID-19 with hematological cancer vs. solid tumors.

- To determine the risk of requiring hospitalization, intensive care, and ventilation in patients with COVID-19 and hematological cancer $v s$. solid tumors.

\section{MATERIALS AND METHODS}

\section{Type of Studies}

Owing to the fact that brief reports were published as letters to the editor in the initial months, articles with the following characteristics were included: cross-sectional or longitudinal observational studies (included in opinion sections or letters to the editor) of series of children with cancer.

Articles that described a single patient and those publications that did not indicate at least one outcome were excluded.

\section{Type of Participants}

Patients aged $<18$ years with a diagnosis of cancer and a positive test for SARS-CoV-2 (by PCR) with reference to the outcomes of interest were included. Patients who underwent a transplant or patients with cancer surveillance for $>5$ years were excluded.

\section{Variables}

Studies that used the PCR test to diagnose the disease were included. The exposure variable was the type of cancer, which was grouped as hematological cancer (acute leukemias and lymphomas) and solid tumors (central nervous system tumors, germ cell tumors, hepatoblastoma, neuroblastoma, osteosarcoma, retinoblastoma, sarcomas, rhabdomyosarcoma, and Wilms' tumor).

\section{Outcomes}

The outcomes recorded were mortality, need for hospitalization, intensive care unit (ICU) care, and ventilation requirement (including invasive and non-invasive ventilation modalities).

\section{Search Strategy}

An exploratory systematic literature review was conducted for the period December 2019 to July 18, 2020 to compare the overall and stratified survival in hematological neoplasms and solid tumors in children aged $<18$ years having cancer and COVID-19.

The information sources used were MEDLINE, TRIP Database, International Clinical Trials Registry Platform (WHO), The Cochrane Library, Wiley, LILACS, and Google Scholar. (Graph 1).

Additionally, the following journals were searched (snowball method): Nature, New England Journal of Medicine, Science, JAMA, editorial de ELSEVIER, Oxford University Press, The Lancet, and MedRxiv. MEDLINE searches were conducted using MESH terms and keywords, without methodological filters by type of article, but only article in English idiom were included. 


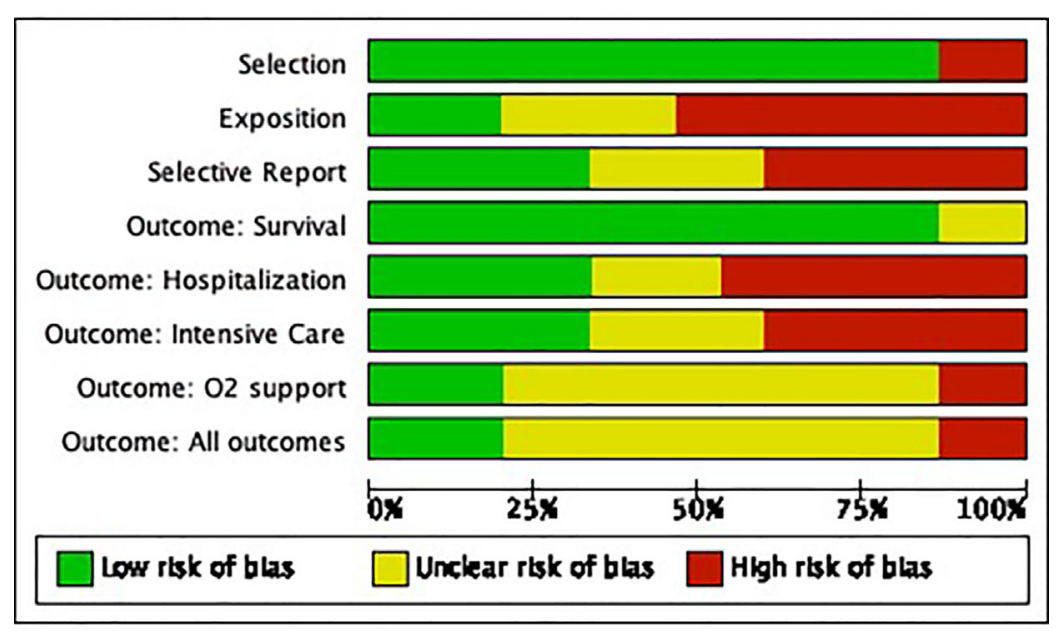

GRAPH 1 | Risk of bias graph of included studies of SARS CoV-2 and cancer in the pediatric population.

Additionally, publications in the reference list of the retrieved full text articles were searched to identify additional relevant studies (snowball method).

The search terms used were keywords or MESH terms (for the pediatric stage, the following were used: pediatrics, children, child, infancy, infant, scholar, and adolescent; for cancer, the following were used: oncology, hematoncologic, cancer, and solid tumors; for the COVID-19 disease, the following were used: SARS-COV-2, COVID-19, and coronavirus 19; and for death, the following were used: mortality, survival, and death).

\section{Data Extraction}

Two reviewers independently assessed the eligibility of the studies for inclusion; the relevant ones were retrieved (according to the eligibility criteria) and subsequently, the necessary information on the characteristics of the included studies was extracted, including participant characteristics, type of exposure, and outcome variables. In both phases, the two reviewers resolved disagreements by consensus; if a disagreement persisted, a third reviewer was consulted. The data obtained were integrated into evidence tables and were verified by the two reviewers. The following information was collected: country of origin, type of design, study objective, study results, if the patient was admitted to the hospital or required ventilation or intensive care, and clinical outcome.

\section{Bias Control}

Bias was controlled using the ROBINS-1 tool for observational studies considering four types of biases: comparability, selection, selective reporting, and outcomes, stratified as present, absent, or doubtful. They were adjusted for each outcome variable (10).

\section{Statistical Analysis}

Quantitative synthesis was performed by meta-analysis using the Cochrane Review software RevMan 5.3. The analysis was performed with the random effect method, and the risk was calculated with odds ratio (OR) and confidence intervals (95\% CI); statistical significance was determined with the Cochran's chi square test. The heterogeneity of the studies was calculated with the Tau and $\mathrm{I}^{2}$ tests. A p value of $<0.05$ was considered statistically significant.

\section{RESULTS}

In the consulted databases, 7,399 articles were identified and eight more from other sources (gray literature), of which 5,078 manuscripts did not match the topic or meet the selection criteria or were repeated. Out of 2,329 abstracts, 46 documents were selected and read in their entirety (Figure 1). Finally, 31 articles were excluded for the following reasons: 22 articles did not meet the selection criteria $(4,11-30)$; four articles included the adult population, and it was not possible to identify pediatric cases $(2,31,32)$; two articles did not include outcomes $(33,34)$ in these cases, the authors were contacted, and in the absence of a response, the articles were excluded-and one article was awaiting peer review (35).

\section{Articles Included}

We included 15 articles $(3,36-49)$ enclosed you will find the Graph 2 with the risk of bias summary (see Graph 1).

\section{Mortality and COVID-19 in Children With Cancer}

Fifteen studies showed survival data from 191 patients with cancer and COVID-19 $(3,45)$ and recorded the death of a patient with Burkitt lymphoma, a type of non-Hodgkin lymphoma. The studies showed an overall mortality of $0.6 \%$ (Supplementary Table 1).

\section{Requirement for Hospitalization}

Two studies (40,43) [de Rojas et al. (40) and Gampel et al. (43)] enabled the analysis of required hospitalization comparing patients with hematological cancer and those with solid tumors. These studies reported the information from 29 patients (eight out of 16 


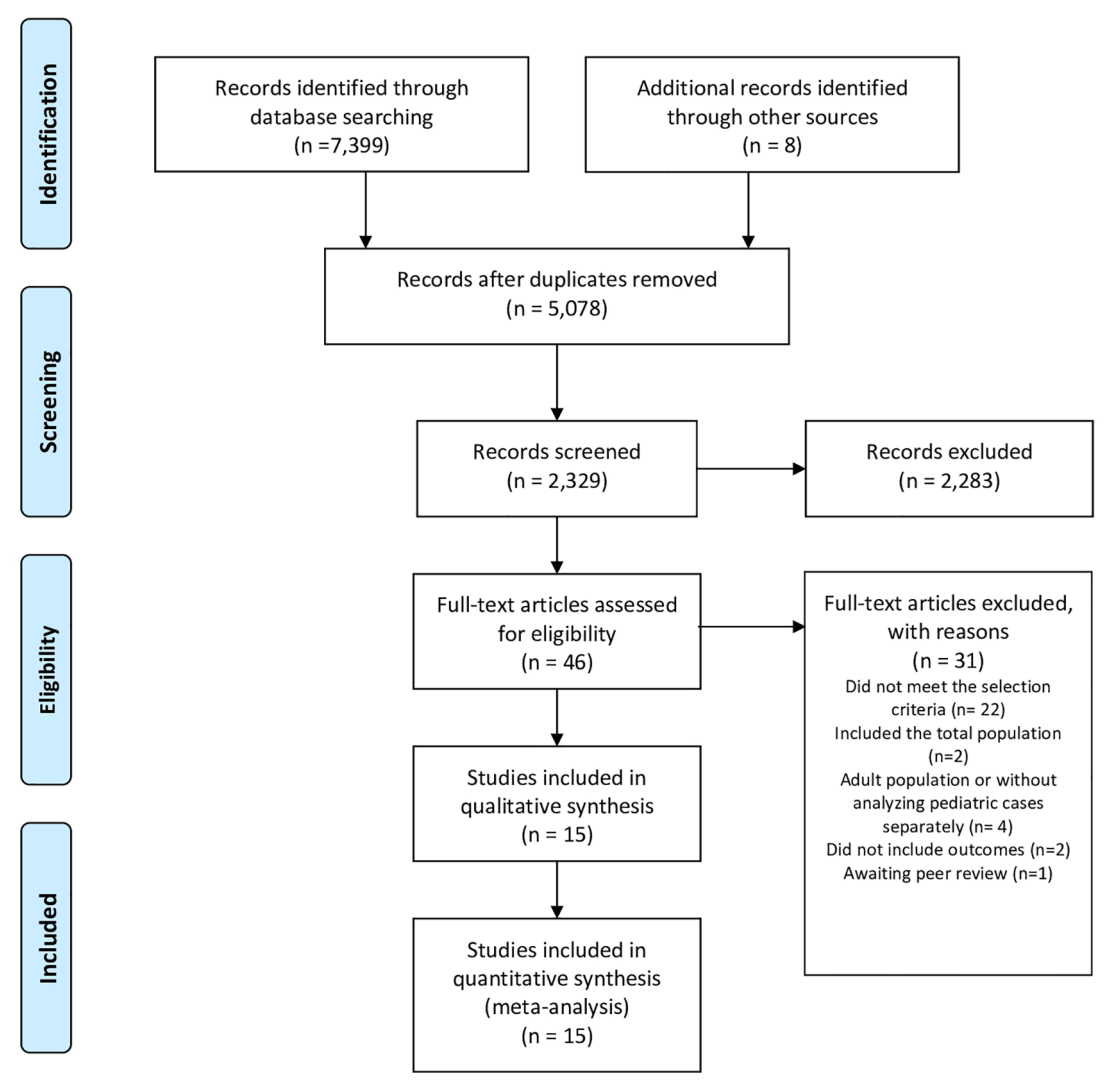

FIGURE 1 | Flow Diagram of included studies.

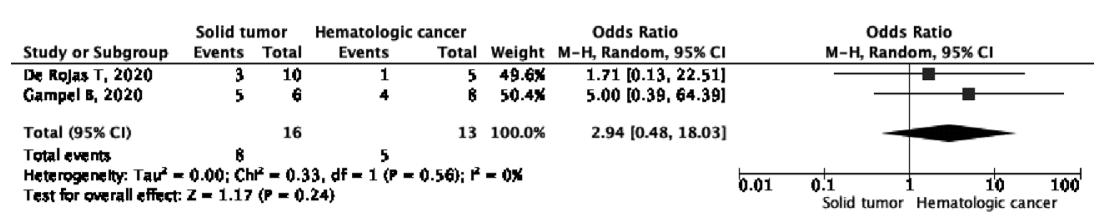

GRAPH 2 | Differences in the need for hospitalization of hematological cancer and solid tumors among patients with SARS CoV-2.

with hematological cancer and five out of 13 with solid tumors), with OR $=2.94$ (95\% CI, 0.48-18.03), $\mathrm{p}=0.24$ and $\mathrm{I}^{2}=0 \%$ (Graph 2).

\section{Requirement for ICU Care}

Information from three articles [Ahmad et al. (36), Gampel et al. (43), and Rossoff et al. (47)] enabled the evaluation of the need for ICU care in 59 patients ( 10 out of 34 patients who presented hematological neoplasms vs. six out of 25 who presented solid tumors), with $\mathrm{OR}=1.42$ (CI 95\%, 0.35-5.81), $\mathrm{p}=0.49$, and test for heterogeneity with $1^{2}=14 \%$ (Graph 3).

\section{Requirement for Assistance of Ventilatory Support Maneuvers}

Tree publications [de Rojas et al. (40), Gampel et al. (43) and Hruzak et al. (45)] described some ventilation assistance maneuver (invasive or non-invasive) in 43 patients (three out of 22 patients with hematological cancer vs. six out of 21 with solid tumors), with an $\mathrm{OR}=0.50$ (CI 95\%, 0.11-2.40), $\mathrm{p}=0.77$, and $1^{2}=0 \%$ (Graph 4).

\section{DISCUSSION}

In this systematic review and meta-analysis, information was collected from published studies out of which, five were multicenter studies conducted in seven countries $(36-44,47)$ showing an overall survival of $99.4 \%$ in patients with cancer under treatment and having COVID-19. All publications were cross-sectional, reflecting a heterogeneous scenario in the clinical course of these patients. Nonetheless, the objective of 
this work was not to compare the outcomes of COVID-19 in healthy children or children with other diseases.

Cancer is a priority in global health because it creates a situation of vulnerability with a high risk of serious complications that require prompt attention by specialized personnel (7). In this investigation, the association with COVID-19 showed a mortality of $<1 \%$ due to the fact that only one death was registered; this value was obtained from the final analysis of the articles. Considering these results, it could be assumed that the current pandemic does not pose a greater risk. This is consistent with a series with similar characteristics in adults. Nonetheless, it should be noted that 14 of the included studies were conducted in cancer hospitals or health centers with conditioned areas for the care of these patients by healthcare professionals specialized in the treatment of complications secondary to chemotherapy. Consequently, it is possible that the same situation in a more general scenario would not yield the same results. Furthermore, it is likely that these results will change once the scientific evidence is updated and data on developing countries are included (such as those located in Latin America and Africa) and with a longer follow-up. For example, in Mexico, the public database of the Ministry of Health showed, up to September 1, 26 deaths in individuals aged $<18$ years with comorbidity of immunosuppression (total in 367), which includes cancer (50). This information could not be added to the meta-analysis because it is not possible to distinguish cancer from other immunosuppressive conditions in the registry. An additional issue is the variation in the cut-off value of patient age to be considered pediatric. This scenario emerged in the study by Olivia Swann et al. (35), who reported the death of a patient with hematological cancer in a 16-19 age range.

Regarding the comparative analysis between tumor types and the need for hospitalization, no differences were found in the three included studies. This is because in most cases, it coincided with the period immediately after chemotherapy, and the information on the deferral of the sessions is insufficient for analysis (51-53). The same scenario is observed in the need for intensive care in the studies showing the causes, which in addition coincided with febrile neutropenia events. In these studies, the information provided does not allow to differentiate whether it is due to septic shock secondary to bacteremia (all the articles with information on treatment presented empirical antimicrobial regimens) or pneumonia (40).

Analysis on the association between the type of neoplasm and the need for oxygen supply did not show a greater risk between the groups. This is in part because as previously mentioned, most of the cases presented with infections secondary to the myelosuppression derived from the treatment. Up to the date of this review, the clinical presentation compatible with the multisystem inflammatory syndrome in children (MIS-C) (54) has not been reported.

The biases of the included studies are a consequence of the fact that the publications present cross-sectional results and that they limit the possibility of adequately predicting the presence of late outcomes (follow-up bias) as well as the absence of information from the entire $n$ of research subjects in the publications, which only describe representative cases, thereby generating selective reporting bias; another bias correspond to the language, since only references in English were included.

It is clear that these results will be subjected to later variations from multicenter groups that currently have cohort designs and from international registries that will include prolonged followups (page of records) adjusted for other potentially confounding variables. Therefore, the authors subscribe to the need to update this review.

With the available information to date, it is not possible to understand the effect that cancer development, age, and type of chemotherapy have on virus infection. In addition, the usefulness

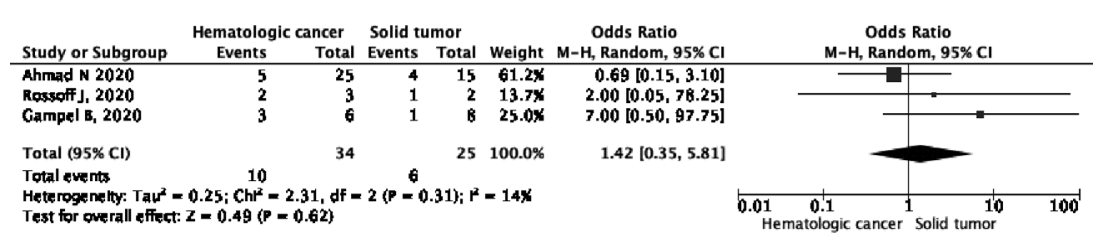

GRAPH 3 | Differences in hospitalization in intensive care for hematological cancer and solid tumors among patients with SARS CoV-2.

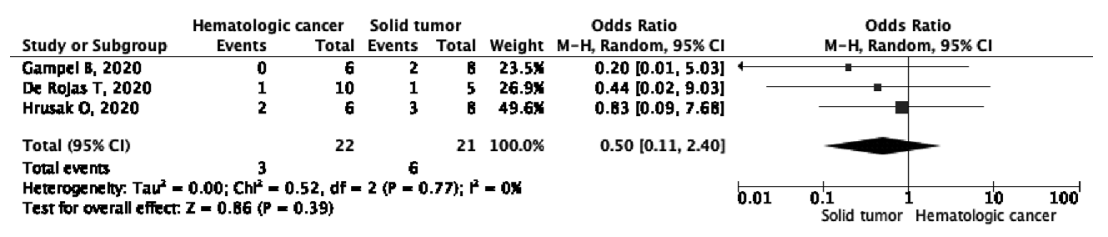

GRAPH 4 | Differences in support with supplemental oxygen for hematological cancer hospitalization and solid tumors among patients with SARS CoV-2. 
of the screening tests in each therapeutic course is unclear, and discriminating the effects of the coronavirus infection from the other complications caused by neoplasia and its treatment represents a challenge.

\section{CONCLUSIONS}

In this meta-analysis, no association was found between COVID19 and the increase in associated mortality in children with cancer. The other outcomes (need for hospitalization/intensive care and ventilation) did not show differences between the types of tumors. This review needs to be updated as soon as information from follow-up studies is available.

\section{DATA AVAILABILITY STATEMENT}

The original contributions presented in the study are included in the article/Supplementary Material. Further inquiries can be directed to the corresponding author.

\section{REFERENCES}

1. Hopkins J. Coronavirus Resource Center. COVID-19 Dashboard by the Center for Systems Science and Engineering (CSSE) at Johns Hopkins University. (2020). Available at: https://coronavirus.jhu.edu/map.html, September 1, 2020.

2. Zhang J, Wang X, Jia X, Li J, Hu K, Chen G, et al. Risk factors for disease severity, unimprovement, and mortality in COVID-19 patients in Wuhan, China. Clin Microbiol Infect (2020) 26:767-72. doi: 10.1016/j.cmi.2020.04.012

3. Balduzzi A, Brivio E, Rovelli A, Rizzari C, Gasperini S, Melzi ML, et al. Lessons after the early management of the COVID-19 outbreak in a pediatric transplant and hemato-oncology center embedded within a COVID-19 dedicated hospital in Lombardia, Italy. Estote parati Bone Marrow Transplant (2020) 10:1-6. doi: 10.2139/ssrn.3559560

4. Dong Y, Mo X, Hu Y, Qi X, Jiang F, Jiang Z, et al. Epidemiology of COVID-19 among children in China. Pediatrics (2020) 145(6):e20200702. doi: 10.1542/ peds.2020-0702

5. Richardson S, Hirsch JS, Narasimhan M, Crawford JM, McGinn T, Davidson $\mathrm{KW}$, et al. Presenting characteristics, comorbidities, and outcomes among 5700 patients hospitalized with COVID-19 in the New York City Area. JAMA (2020) 323:252-29. doi: 10.1001/jama.2020.6775

6. Pathak EB, Salemi JL, Sobers N, Menard J, Hambleton IR. COVID-19 in children in the United States: Intensive care admissions, estimated total infected, and projected numbers of severe pediatric cases in 2020. J Public Health Manag Pract (2020) 26:325-33. doi: 10.1097/PHH. 0000000000001190

7. Bray F, Ferlay J, Soerjomataram I, Siegel RL, Torre LA, Jemal A. Global cancer statistics 2018: GLOBOCAN estimates of incidence and mortality worldwide for 36 cancers in 185 countries. CA Cancer J Clin (2018) 68:394-424. doi: $10.3322 /$ caac. 21492

8. Chen Z, Xiong H, Li JX, Li H, Tao F, Yang YT, et al. COVID-19 with postchemotherapy agranulocytosis in childhood acute leukemia: a case report. Zhonghua Xue Ye Xue Za Zhi (2020) 41:341-3. doi: 10.3760/cma.j.issn.02532727.2020.0004.

9. Bouffet E, Challinor J, Sullivan M, Biondi A, Rodriguez-Galindo C, PritchardJones K. Early advice on managing children with cancer during the COVID19 pandemic and a call for sharing experiences. Pediatr Blood Cancer (2020) 67:e28327. doi: 10.1002/pbc.28327

10. Schunemann HJ, Cuello C, Akl EA, Mustafa RA, Meerpohl JJ, Thayer K, et al. GRADE Working Group. GRADE guidelines: 18. How ROBINS-I and other tools to assess risk of bias in nonrandomized studies should be used to rate the

\section{AUTHOR CONTRIBUTIONS}

ED-A, DÁ-M, and HM-G: manuscript writing. LJ-V and MK-K: substantial contributions and manuscript review. All authors contributed to the article and approved the submitted version.

\section{ACKNOWLEDGMENTS}

The authors thank the General Directorate and Research Directorate of the Hospital Infantil de México Federico Gómez (Dr Jaime Nieto Zermeño and Dr Juan Garduño Espinosa) for their interest in the subject and for providing the required data for the authors to perform this meta-analysis.

\section{SUPPLEMENTARY MATERIAL}

The Supplementary Material for this article can be found online at: https://www.frontiersin.org/articles/10.3389/fonc.2020.608282/ full\#supplementary-material

certainty of a body of evidence. J Clin Epidemiol (2019) 111:105-14. doi: 10.1016/j.jclinepi.2018.01.012

11. Gonzalez-Dambrauskas S, Vasquez-Hoyos P, Camporesi A, Díaz-Rubio F, Piñeres-Olave BE, Fernández-Sarmiento J, et al. CRITICAL CORONAVIRUS AND KIDS EPIDEMIOLOGY CAKE STUDY. Pediatric critical care and COVID-19. Pediatrics (2020) 146(3):e20201766. doi: 10.1542/peds.2020-1766

12. Liguoro I, Pilotto C, Bonanni M, Ferrari ME, Pusiol A, Nocerino A, et al. SARS-COV-2 infection in children and newborns: a systematic review. Eur J Pediatr (2020) 179:1029-46. doi: 10.1007/s00431-020-03684-7

13. Sun D, Li H, Lu XX, Xiao H, Ren J, Zhang FR, et al. Clinical features of severe pediatric patients with coronavirus disease 2019 in Wuhan: a single center's observational study. World J Pediatr (2020) 16:251-9. doi: 10.1007/s12519020-00354-4

14. Wu H, Zhu H, Yuan C, Yao C, Luo W, Shen X, et al. Clinical and immune features of hospitalized pediatric patients with coronavirus disease 2019 (COVID-19) in Wuhan, China. JAMA Netw Open (2020) 3:e2010895. doi: 10.1001/jamanetworkopen.2020.10895

15. Chao JY, Derespina KR, Herold BC, Goldman DL, Aldrich M, Weingarten J, et al. Clinical characteristics and outcomes of hospitalized and critically ill children and adolescents with coronavirus disease 2019 at a tertiary care medical center in New York City. J Pediatr (2020) 223:14-19 e12. doi: 10.1016/j.jpeds.2020.05.006

16. Sieni E, Pegoraro F, Casini T, Tondo A, Bortone B, Moriondo M, et al. Favourable outcome of coronavirus disease 2019 in a 1-year-old girl with acute myeloid leukaemia and severe treatment-induced immunosuppression. Br J Haematol (2020) 189:e222-4. doi: 10.1111/bjh.16781

17. Lu X, Zhang L, Du H, Zhang J, Li YY, Qu J, et al. Chinese Pediatric Novel Coronavirus Study Team. SARS-CoV-2 infection in children. N Engl J Med (2020) 382:1663-5. doi: 10.1056/NEJMc2005073

18. Schied A, Trovillion E, Moodley A. SARS-CoV-2 infection in a neutropenic pediatric patient with leukemia: Addressing the need for universal guidelines for treatment of SARS-CoV-2-positive, immunocompromised patients. Pediatr Blood Cancer (2020) 9:e28546. doi: 10.22541/au.159200606.64100827

19. Yang C, Li C, Wang S, National Clinical Research Center for Child H, Disorders, Children's Oncology Committee of Chinese Research Hospital A. Clinical strategies for treating pediatric cancer during the outbreak of 2019 novel coronavirus infection. Pediatr Blood Cancer (2020) 67:e28248. doi: $10.1002 / \mathrm{pbc} .28248$

20. Baruchel A, Bertrand Y, Boissel N, Brethon B, Ducassou S, Gandemer V, et al. COVID-19 and acute lymphoblastic leukemias of children and adolescents: First recommendations of the Leukemia committee of the French Society for 
the fight against Cancers and Leukemias in children and adolescents (SFCE). Bull Cancer (2020) 107:629-32. doi: 10.1016/j.bulcan.2020.04.003

21. Sullivan M, Bouffet E, Rodriguez-Galindo C, Luna-Fineman S, Khan MS, Kearns P, et al. The COVID-19 pandemic: A rapid global response for children with cancer from SIOP, COG, SIOP-E, SIOP-PODC, IPSO, PROS, CCI, and St Jude Global. Pediatr Blood Cancer (2020) 67:e28409. doi: 10.1002/pbc.28409

22. Shekerdemian LS, Mahmood NR, Wolfe KK, Riggs BJ, Ross CE, McKiernan CA, et al. International COVID-19 PICU Collaborative. Characteristics and outcomes of children with coronavirus disease 2019 (COVID-19) infection admitted to US and Canadian pediatric intensive care units. JAMA Pediatr (2020) 174(9):868-73. doi: 10.1001/pediatrics.2020.1948

23. Saab R, Obeid A, Gachi F, Boudiaf H, Sargsyan L, Al-Saad K, et al. Impact of the coronavirus disease 2019 (COVID-19) pandemic on pediatric oncology care in the Middle East, North Africa, and West Asia Region: A report from the Pediatric Oncology East and Mediterranean (POEM) Group. Cancer (2020) 126(18):4235-45. doi: 10.02/CNCR.33075

24. Sajid MI, Altaf S, Mushtaq N, Belgaumi A, Fadoo Z. Pediatric hematology oncology during SARS-CoV-2: A brief communication of 28 patients and changes in clinical practice from a single institute in Pakistan. Pediatr Blood Cancer (2020) 1:e28527. doi: 10.22541/au.159069401.17235610

25. Mantovani A, Rinaldi E, Zusi C, Beatrice G, Saccomani MD, Dalbeni A. coronavirus disease 2019 (COVID-19) in children and/or adolescents: a metaanalysis. Pediatr Res (2020). doi: 10.1038/S31390-020-1015-2

26. Ding YY, Ramakrishna S, Long AH, Phillips CA, Montiel-Esparza R, Diorio CJ, et al. Delayed cancer diagnoses and high mortality in children during the COVID19 pandemic. Pediatr Blood Cancer (2020) 9:e28427. doi: 10.1002/pbc.28427

27. Auletta JJ, Adamson PC, Agin JE, Kearns P, Kennedy S, Kieran MW, et al. Pediatric cancer research: Surviving COVID-19. Pediatr Blood Cancer (2020) 9:e28435. doi: 10.22541/au.158888178.87297637

28. Seth T, Shankar A, Roy S, Saini D. Hemato- Oncology Care in COVID-19 Pandemic: Crisis within a Crisis. Asian Pac J Cancer Prev (2020) 21:1173-5. doi: 10.31557/APJCP.2020.21.5.1173

29. Kaspers GJL. COVID-19: how will this impact children with cancer, now and in the future? Expert Rev Anticancer Ther (2020) 20:527-9. doi: 10.1080/ 14737140.2020 .1781621

30. Parasole R, Stellato P, Conter V, De Matteo A, D'Amato L, Colombini A, et al. Collateral effects of COVID-19 pandemic in pediatric hematooncology: Fatalities caused by diagnostic delay. Pediatr Blood Cancer (2020) 67: e28482. doi: 10.1002/pbc.28482

31. Dai M, Liu D, Liu M, Zhou F, Li G, Chen Z, et al. Patients with cancer appear more vulnerable to SARS-CoV-2: A multicenter study during the COVID-19 Outbreak. Cancer Discovery (2020) 10:783-91. doi: 10.1158/2159-8290.CD-20-0422

32. Mehta V, Goel S, Kabarriti R, Cole D, Goldfinger M, Acuna-Villaorduna A, et al. Case fatality rate of cancer patients with COVID-19 in a New York hospital system. Cancer Discovery (2020) 10:935-41. doi: 10.1158/2159-8290.CD-20-0516

33. Terenziani M, Massimino M, Biassoni V, Casanova M, Chiaravalli S, Ferrari A, et al. SARS-CoV-2 disease and children under treatment for cancer. Pediatr Blood Cancer (2020) 9:e28346. doi: 10.1002/pbc.28346

34. Robilotti EV, Babady NE, Mead PA, Rolling T, Perez-Johnston R, Bernardes M, et al. Determinants of COVID-19 disease severity in patients with cancer. Nat Med (2020) 26:1218-23. doi: 10.1038/s41591-020-0979-0

35. Swann O, Holden K, Turtle L, Pollock L, Fairfield CJ, Drake TM, et al. ISARIC Coronavirus Clinical Characterisation Consortium (ISARIC4C) Investigators. Clinical characteristics of children and young people hospitalised with covid19 in the United Kingdom: prospective multicentre observational cohort study. medRxiv (2020) m3249. doi: 10.1136/BMJ.m3249

36. Ahmad N, Essa MF, Sudairy R. Impact of Covid19 on a tertiary care pediatric oncology and stem cell transplant unit in Riyadh, Saudi Arabia. Pediatr Blood Cancer (2020) 9:e28560. doi: 10.1002/pbc.28560

37. Andre N, Rouger-Gaudichon J, Brethon B, Phulpin A, Thébault É, Pertuisel S, et al. COVID-19 in pediatric oncology from French pediatric oncology and hematology centers: High risk of severe forms? Pediatr Blood Cancer (2020) 67:e28392. doi: 10.1002/pbc.28392

38. Boulad F, Kamboj M, Bouvier N, Mauguen A, Kung AL. COVID-19 in Children With Cancer in New York City. JAMA Oncol (2020) 6:1459-60s. doi: 10.1001/jamaoncol.2020.2028

39. Cesaro S, Compagno F, Zama D, Meneghello L, Giurici N, Soncini E, et al. Screening for SARS-CoV-2 infection in pediatric oncology patients during the epidemic peak in Italy. Pediatr Blood Cancer (2020) 67:e28466. doi: 10.1002/ pbc. 28466

40. de Rojas T, Perez-Martinez A, Cela E, Baragaño M, Galán V, Mata C, et al. COVID-19 infection in children and adolescents with cancer in Madrid. Pediatr Blood Cancer (2020) 67:e28397. doi: 10.1002/pbc.28397

41. Ferrari A, Zecca M, Rizzari C, Porta F, Provenzi M, Marinoni M, et al. Children with cancer in the time of COVID-19: An 8-week report from the six pediatric onco-hematology centers in Lombardia, Italy. Pediatr Blood Cancer (2020) 67:e28410. doi: 10.1002/pbc.28410

42. Flores V, Miranda R, Merino L, González C, Serrano C, Solano M, et al. SARSCoV-2 infection in children with febrile neutropenia. Ann Hematol (2020) 99:1941-2. doi: 10.1007/s00277-020-04115-1

43. Gampel B, Troullioud Lucas AG, Broglie L, Gartrell-Corrado RD, Lee MT, Levine J, et al. COVID-19 disease in New York City pediatric hematology and oncology patients. Pediatr Blood Cancer (2020) 9:e28420. doi: 10.1002/ pbc. 28420

44. Garazzino S, Montagnani C, Dona D, Meini A, Felici E, Vergine G, et al. Italian SITIP-SIP SARS-CoV-2 paediatric infection study group. Multicentre Italian study of SARS-CoV-2 infection in children and adolescents, preliminary data as at 10 April 2020. Euro Surveill (2020) 25(18):2000600. doi: 10.2807/1560-7917.ES.2020.25.18.2000600

45. Hrusak O, Kalina T, Wolf J, Balduzzi A, Provenzi M, Rizzari C, et al. Flash survey on severe acute respiratory syndrome coronavirus-2 infections in paediatric patients on anticancer treatment. Eur J Cancer (2020) 132:11-6. doi: 10.1016/j.ejca.2020.03.021

46. Issitt RW, Booth J, Bryant WA, Spiridou A, Taylor AM, du Pré P, et al. Children with COVID-19 at a specialist centre: initial experience and outcome. Lancet Child Adolesc Health (2020) 4:e30-1. doi: 10.1016/S23524642(20)30204-2

47. Rossoff J, Patel AB, Muscat E, Kociolek LK, Muller WJ. Benign course of SARS-CoV-2 infection in a series of pediatric oncology patients. Pediatr Blood Cancer (2020) 9:e28504. doi: 10.1002/pbc.28504

48. Stokes CL, Patel PA, Sabnis HS, Mitchell SG, Yildirim IB, Pauly MG. Severe COVID-19 disease in two pediatric oncology patients. Pediatr Blood Cancer (2020) 67:e28432. doi: 10.1002/pbc.28432

49. Zachariah P, Johnson CL, Halabi KC, Ahn D, Sen AI, Fischer A, et al. Epidemiology, clinical features, and disease severity in patients with coronavirus disease 2019 (COVID-19) in a children's hospital in New York City, New York. JAMA Pediatr (2020) 174(10):e202430. doi: 10.1001/ jamapediatrics.2020.2430

50. Gobierno de México. CONACYT - CentroGeo - GeoInt - DataLab. Covid-19 México. (2020). Available at: https://coronavirus.gob.mx/datos/, September 17, 2020.

51. Molica M, Mazzone C, Cordone I, Pasquale A, Niscola P, de Fabritiis P. SARS$\mathrm{CoV}-2$ infection anxieties and general population restrictions delay diagnosis and treatment of acute haematological malignancies. Br J Haematol (2020) 190:e5-8. doi: 10.1111/bjh.16785

52. Ruggiero A, Romano A, Attina G. Facing the COVID-19 outbreak in children with cancer. Drugs Context (2020) 190(1):e5-8. doi: 10.7573/DIC.2020-4-12

53. Faura A, Rives S, Lassaletta A, Sebastián E, Madero L, Huerta J, et al. Initial report on Spanish pediatric oncologic, hematologic, and post stem cell transplantation patients during SARS-CoV-2 pandemic. Pediatr Blood Cancer (2020) 67(9):e28557. doi: 10.1002/pbc.28557

54. Rowley AH. Understanding SARS-CoV-2-related multisystem inflammatory syndrome in children. Nat Rev Immunol (2020) 20(8):453-4. doi: 10.1038/ s41577-020-0367-5

Conflict of Interest: The authors declare that the research was conducted in the absence of any commercial or financial relationships that could be construed as a potential conflict of interest.

Copyright (๑) 2021 Dorantes-Acosta, Ávila-Montiel, Klünder-Klünder, Juárez-Villegas and Márquez-González. This is an open-access article distributed under the terms of the Creative Commons Attribution License (CC BY). The use, distribution or reproduction in other forums is permitted, provided the original author $(s)$ and the copyright owner(s) are credited and that the original publication in this journal is cited, in accordance with accepted academic practice. No use, distribution or reproduction is permitted which does not comply with these terms. 